\title{
Variability of the total ozone trend over Europe for the period 1950-2004 derived from reconstructed data
}

\author{
J. W. Krzyścin and J. L. Borkowski \\ Institute of Geophysics, Polish Academy of Sciences, Warsaw, Poland \\ Received: 28 November 2007 - Published in Atmos. Chem. Phys. Discuss.: 4 January 2008 \\ Revised: 7 May 2008 - Accepted: 13 May 2008 - Published: 4 June 2008
}

\begin{abstract}
The total ozone data over Europe are available for only few ground-based stations in the pre-satellite era disallowing examination of the spatial trend variability over the whole continent. A need of having gridded ozone data for a trend analysis and input to radiative transfer models stimulated a reconstruction of the daily ozone values since January 1950. Description of the reconstruction model and its validation were a subject of our previous paper. The data base used was built within the objectives of the COST action 726 "Long-term changes and climatology of UV radiation over Europe". Here we focus on trend analyses. The long-term variability of total ozone is discussed using results of a flexible trend model applied to the reconstructed total ozone data for the period 1950-2004. The trend pattern, which comprises both anthropogenic and "natural" component, is not a priori assumed but it comes from a smooth curve fit to the zonal monthly means and monthly grid values. The ozone long-term changes are calculated separately for cold (October-next year April) and warm (May-September) seasons. The confidence intervals for the estimated ozone changes are derived by the block bootstrapping. The statistically significant negative trends are found almost over the whole Europe only in the period 1985-1994. Negative trends up to $-3 \%$ per decade appeared over small areas in earlier periods when the anthropogenic forcing on the ozone layer was weak. The statistically positive trends are found only during warm seasons 1995-2004 over Svalbard archipelago. The reduction of ozone level in 2004 relative to that before the satellite era is not dramatic, i.e., up to $\sim-5 \%$ and $\sim-3.5 \%$ in the cold and warm subperiod, respectively. Present ozone level is still depleted over many popular resorts in southern Europe and northern Africa. For high latitude regions the trend overturning could be inferred in last decade
\end{abstract}

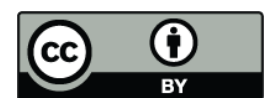

Correspondence to: J. W. Krzyścin (jkrzys@igf.edu.pl)
(1995-2004) as the ozone depleted areas are not found there in 2004 in spite of substantial ozone depletion in the period 1985-1994.

\section{Introduction}

Negative trends in the ozone content in the atmosphere in the mid- and high latitude regions over both hemisphere and anticipated increase of the surface UV radiance (UVR) there triggered numerous studies on variability of UVR in different time scales and its influencing factors including ozone, aerosols, and clouds (Bais et al., 2007, and references herein).

The time series of the surface UV-B measurements longer than 2 decades are rather rare. 14 sites in the United States were analyzed by Weatherhead et al. (1997) and only one site, Belsk, in Europe by Borkowski (2000). Length of reliable data records is up to $10-15$ year for the most European UV observing stations. It is recognised that such period is not adequate to carry out trend analyses (Weatherhead et al., 1998). However, recent studies show possibilities to reconstruct the surface UVR using variables (total ozone, cloud/aerosol optical depth) directly affecting UVR (e.g., Kaurola et al., 2000; den Outer et al., 2000; Fioletov et al., 2001). The pyranometer and other meteorological data (sunshine duration and cloud cover) serve as proxies for the combined cloud/aerosols effects on UVR. Comparison of the European UV reconstruction models under the COST action 726 "Long-term changes and climatology of UV radiation over Europe" showed that past UV field could be accurately estimated using models taking into account only total ozone and pyranometric data (Koepke, et al., 2006). The reconstructed datasets, which can extend backward in time to as early as the beginning of total ozone and pyranometer observations, would help to examine the UVR variability over Europe in periods without UV measurements.

Published by Copernicus Publications on behalf of the European Geosciences Union. 
Observations of the total (Sun + sky) solar irradiance integrated over the whole spectral range $(\sim 300-3000 \mathrm{~nm})$ using pyranometers belong to standard measurements carried out at many meteorological stations. Since the late 1970s the global distribution of ozone has been available from satellite observations. Much less is known about the stratospheric ozone during earlier periods. Current data archive centred at the World Ozone and Ultraviolet Data Center (WOUDC) in Toronto, Canada contains only few continuous total ozone records starting before International Geophysical Year in 1957. Thus for a purpose of the surface UV reconstruction over Europe (within the framework of the COST-726 action objectives) a statistical model has been developed to simulate daily total ozone values. The ozone data base covering Europe has been built since 1 January 1950 (Krzyścin, 2008). Here we present results concerning the long-term variability of total ozone over Europe for the period 1950-2004. There were many studies focusing on trends in ozone but usually an anthropogenic component of the long-term variability was extracted from the data. Our objective is to estimate the longterm ozone forcing on the surface UV. Thus we calculate the trend component of total ozone that comprises both the anthropogenic and "natural" effects. The normal level of UV irradiation is high during the warm period of the year and decisive for the annual accumulated UV doses. Moreover, outdoor people activities are also more frequent in this part of the year. The trend analysis will be applied separately to subsets of the ozone data, warm (May-September) and cold (October-next year April). It allows to estimate more precisely risk of the UV overexposure due to the ozone changes.

\section{Total ozone data base}

Statistical model has been proposed within the framework of the COST-726 action to reproduce past total ozone variations over Europe to be used for surface UV simulations (Krzyścin, 2008). The assimilated data base of total column ozone measurements from satellites covering the whole globe, known as NIWA total ozone data base (named after affiliation of leading author Greg Bodeker - National Institute of Water and Atmosphere Research, Lauder, New Zealand) is used as input to our regression model. The NIWA data were homogenized by a comparison with the ground-based Dobson spectrophotometer stations. The data base was widely used in various studies of global ozone behaviour (Bodeker et al., 2001 and 2005; Fioletov et al., 2002; WMO, 2003 and 2007).

The COST-726 ozone reconstruction model consists of two-step regression. The first step is a regression of the monthly means of NIWA total ozone on various standard ozone explanatory variables, i.e., indices of the atmospheric circulation and meteorological variables (temperature, absolute vorticity). The vorticity and temperature are taken from NCEP/NCAR Reanalysis-1 data base. The meteorological variables are based on GCM simulations controlled by the radiosonde results (before the satellite era) and the satellite results afterwards. Next is a regression of the daily departures of NIWA total ozone from the total ozone monthly means. Here, the explanatory variables are deviations of the daily values of meteorological variables from their monthly means. Finally, the modelled daily total ozone is obtained as a sum of terms being multiplication of regression constants and pertaining explanatory variables that were selected as important regressors using the multivariate adaptive regression splines (MARS) technique (Friedman, 1979). The quality of the data base is assured by a comparison of the reconstructed total ozone with the ground-based data from several Dobson stations functioning in the early 1950s and 1960 s. The model explains $\sim 70-80 \%$ variance of the ozone data collected before the satellite era. Bias and the long-term drift between the reconstructed and measured Dobson ozone are within a range of $\pm 2 \%$.

The reconstructed COST-726 ozone data base consists of daily total values since 1 January 1950 for a longitudelatitude rectangle with the length from $25.625^{\circ} \mathrm{W}$ to $35.625^{\circ} \mathrm{E}$ and the width from $30.5^{\circ} \mathrm{N}$ to $80.5^{\circ} \mathrm{N}$. The grid resolution is $1^{\circ}$ in the latitudinal and $1.25^{\circ}$ in the longitudinal direction. The data base is available at address http://tau.igf.edu.pl $\sim$ jkrzys with the data reading software and files describing the data format and performance of the model.

The total ozone distribution over Europe in March and July shown in Fig. 1 and Fig. 2, respectively, have been calculated averaging the daily total ozone values taken from the data base. Top figures represent the overall long-term monthly means for the period 1950-1959. Bottom figures provide the departures of the overall long-term monthly means for the period 1995-2004 relative to the 1950-1959 means in percent of the latter means. A substantial ozone depletion over Europe can be inferred from a comparison between the modelled ozone means in the last and first decade of analyzed data. Further in the text we present results of trend analysis and visualize the spatial and temporal variability of the total ozone field over Europe.

\section{Trend model}

In previous studies of the total ozone trends authors focused on extraction of component of the long-term variability being result of anthropogenic forcing (release of various chemicals like freons and halogens destroying the ozone layer), Chipperfield et al. (2007) and references herein. The natural variations of total ozone were parameterized and removed from the series, e.g. the 11-year solar signal, QBO, etc. Our approach is different when searching for the UV response to changing the ozone layer. We would like to estimate the long-term changes in total ozone comprising both anthropogenic and "natural" effects. 

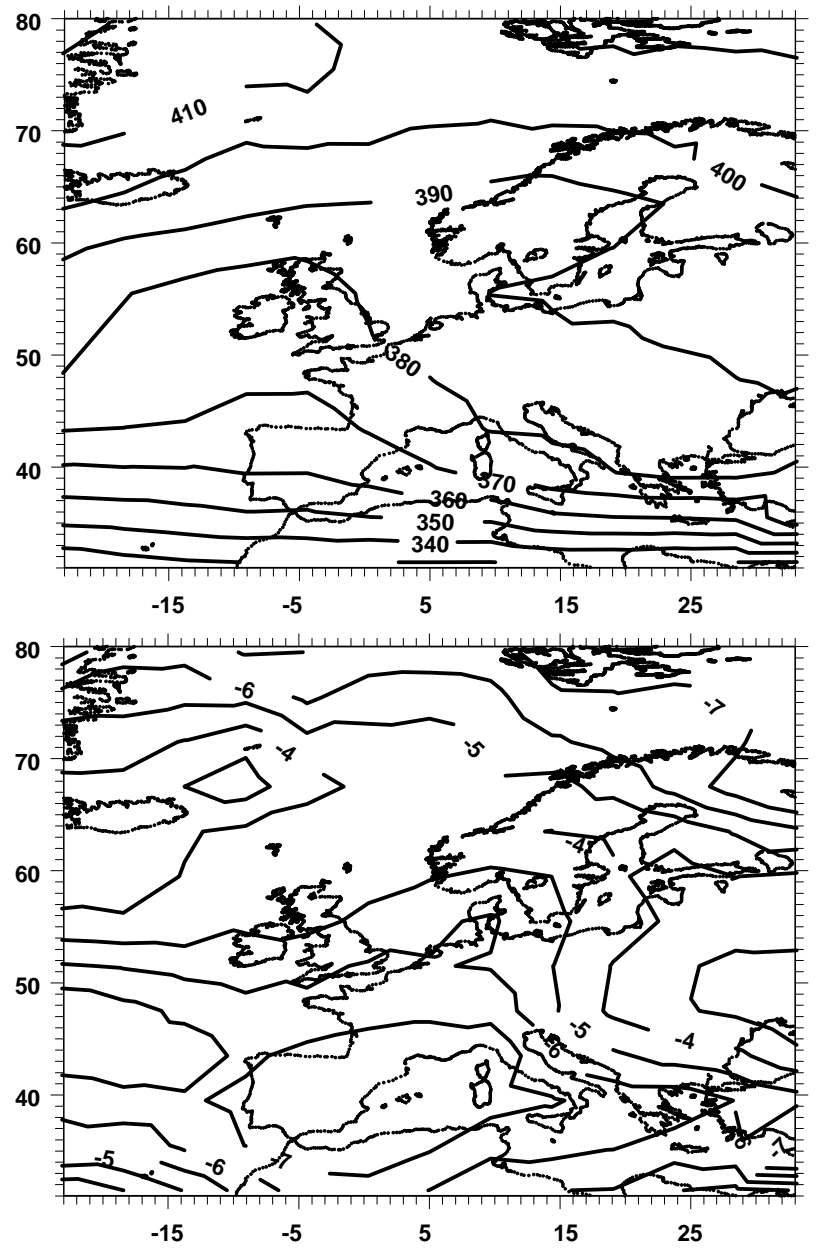

Fig. 1. Mean total ozone (DU) in March for the period 1950-1959 (top), the difference between the mean total ozone in March for period 1995-2004 and that for the period 1950-1959 in percent of the latter means (bottom).

The long-term variability of total ozone was usually derived from a straight line fit to the whole analyzed time series or its subsets (e.g., Reinsel et al., 2002; WMO, 2003). A comparison of slopes of the regression lines enables to infer temporal variations of the long-term trend in last decades. Recently a concept of trend evaluation using a smooth curve fit to the ozone data has been evolving (Harris et al., 2003; Krzyścin et al., 2005; Oltmans et al., 2006; and Krzyścin, 2006). The trend means continuing and smooth change over a given time period. A difference between the curve's values at the end and beginning of selected time period divided by the length of the period gives the trend value. A model using such concept is the so-called flexible trend model and it is also used here:

$$
\Delta \mathrm{O}_{3}\left(t_{m, K}\right)=F\left(t_{m, K}\right)+\operatorname{Noise}\left(t_{m, K}\right)
$$

where $\Delta \mathrm{O}_{3}\left(t_{m, K}\right)$ is the relative deviation of the modeled total ozone monthly mean for calendar month $m$ and year $K$
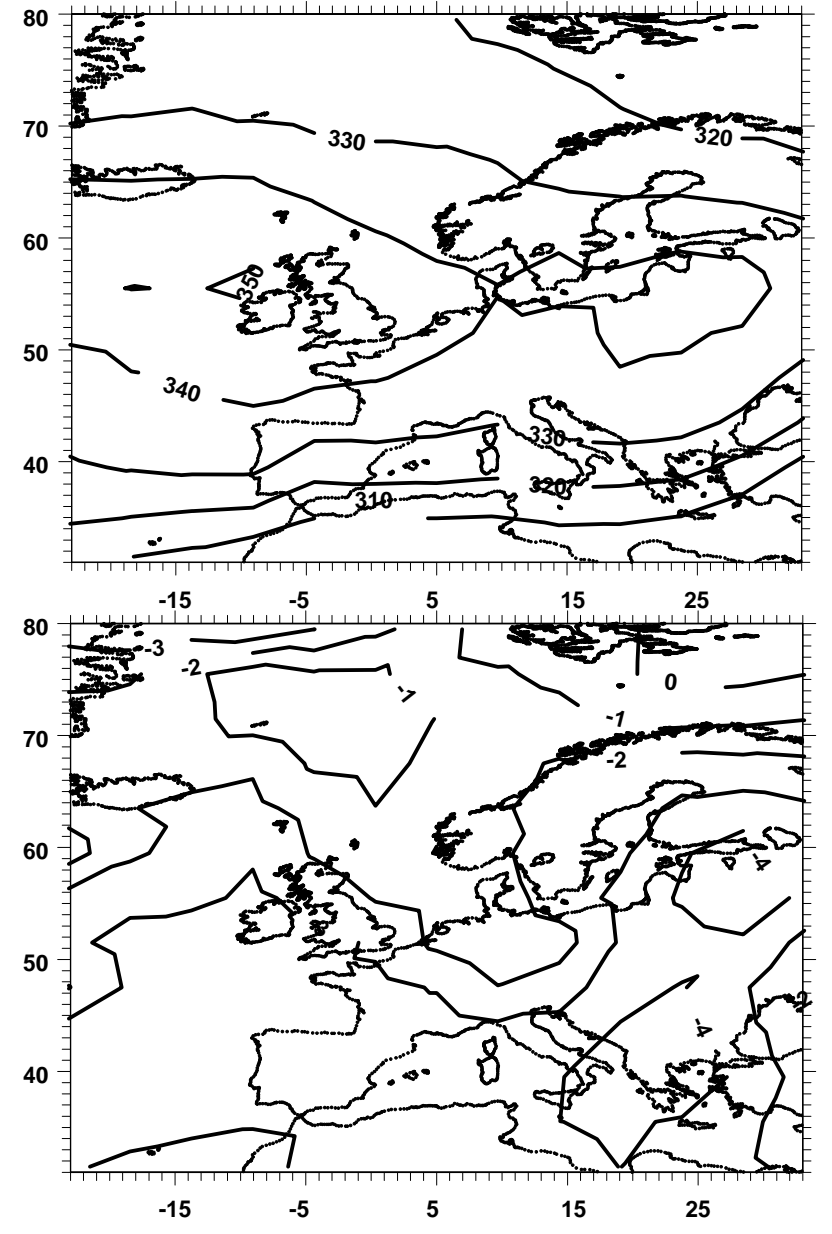

Fig. 2. Same as Fig. 1 but for July.

relative to the long-term 1950-1978 monthly mean for month $m$ in percent of the long-term mean, $F\left(t_{m, K}\right)$ represents a low frequency trend component derived by smoothing of the data, Noise $\left(t_{m, K}\right)$ is a short-term component that is calculated as departures from the smoothed curve. The model is run separately for the cold and warm subset of the year for each grid point.

Various smoothing techniques are possible, for example, wavelets, locally weighted regression (LOWES), kernel, smoothing spline, etc. These procedures could be found in the present statistical software (e.g. S-Plus 4 Guide to Statistics, 1997). The most essential problem in the data smoothing for the trend analysis is selection of a smoothness level, i.e., what scales of the time series variability should be retained for the trend determination. The level could be arbitrarily chosen for most of presently used smoothers. For example, Fig. 3 (top) shows possible candidates for trend components extracted from an application of the kernel smoother with different temporal bandwidths (from 2-year up to 55year) to the relative deviations of monthly means of total ozone for the period 1950-2004, which are averaged over the 

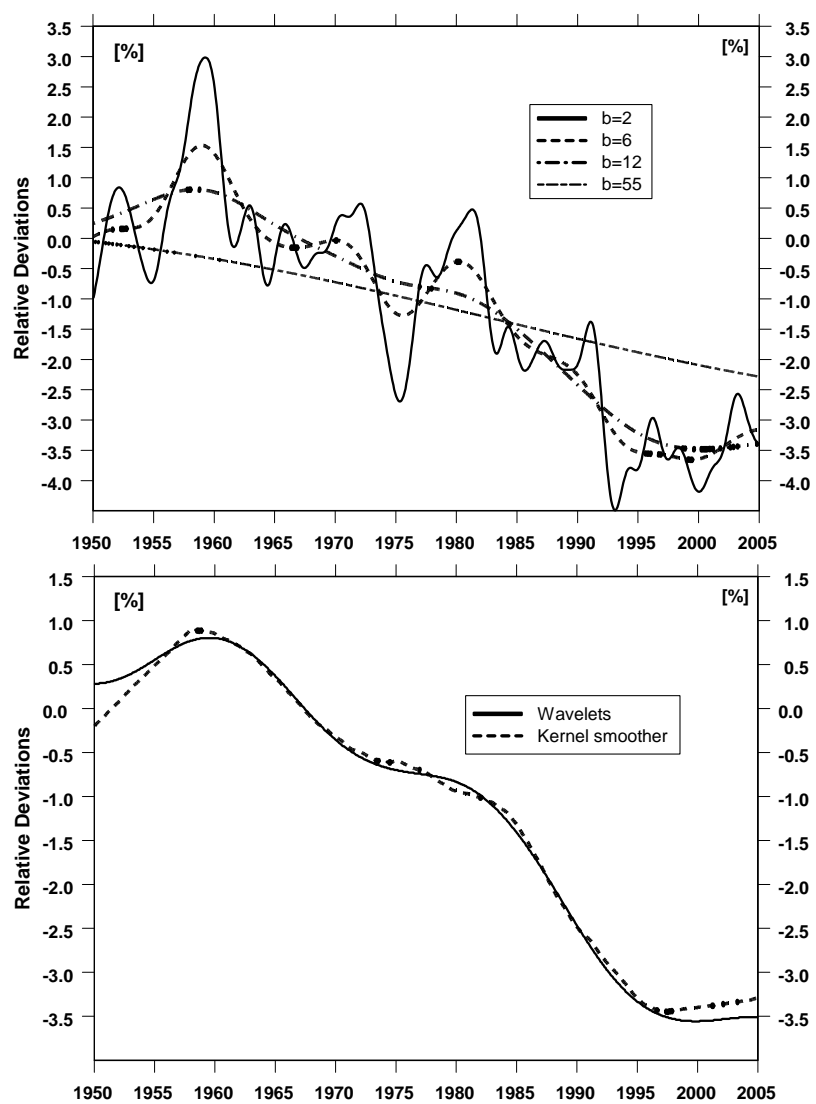

Fig. 3. Smooth pattern of the zonal means of total ozone for the $40^{\circ}-45^{\circ} \mathrm{N}$ latitudinal belt over Europe; application of the kernel smoother with different temporal (in years) bandwidth $b-$ (a), a smooth component of the wavelet multiresolution decomposition, and the kernel smoother with $b=8-$ year $-(\mathbf{b})$.

band $40^{\circ}-45^{\circ} \mathrm{N}$. It is difficult to decide which curve provides a trend component. Figure 3 (top) shows that a linear approximation, as provided by the kernel smoother with bandwidth of 55-year, underestimates the ozone values at the beginning of the time series and overestimates at the end. The linear trend concept could not be applied to the whole analyzed period as a lessening of the ozone negative trend or leveling off seems to occur since the mid 1990s.

The wavelet analysis may facilitate the process of proper selection of the smoothness level. The wavelet multiresolution decomposition separates the series into components, and the so-called "smooth" component is appropriate for trend analyses (e.g., Borkowski, 2002). Such component of the ozone time series together with the plot of the series obtained by the application of the kernel smoother with bandwidth 8year are shown in Fig. 3 (bottom). In the performed multiresolution decomposition non-decimated wavelet transform was used because such a transform is translation invariant and in comparison with ordinary discrete wavelet transform provides better resolution at longer time scales (Bruce and Gao,
1996). Thus, it seems that the curve extracted by the kernel smoother with bandwidth 8-year could be treated as the trend component for 55-year time series. We decide to use such kernel smoother for all examined time series in spite of that wavelet smoother has some advantages over other smoother. The wavelets smoother requires equidistance data points, which are lacking for high latitude regions (no data during polar night) or seasonal data (time series for selected calendar months in the year).

The $95 \%$ confidence ranges for the trend curve possible variability are derived here by the block bootstrapping. The bootstrap belongs to the category of nonparametric statistical methods. It is able to simulate the probability distribution of any statistics without making additional assumptions related to the temporal or spatial covariance structure of the variables. Resampling with replacement of the original record provides a sample of potential time series. However, a construction of potential representatives of the original record must preserve the temporal structure of the original one. In our approach many hypothetical time series of $\Delta \mathrm{O}_{3}\left(t_{m, K}\right)$ are generated by a random resampling of the yearly blocks taken from Noise $\left(t_{m, K}\right)$ time series,

$\operatorname{Noise}^{*}\left(t_{m, K}\right)=\operatorname{Noise}\left(t_{m, K^{*}}\right)$

where Noise* $\left(t_{m, K}\right)$ is potential noise term in calendar month $m$ and year $K$ being the same as noise term in year $K^{*}, K^{*}$ is randomly selected year between 1950 and 2004. The same $K^{*}$ is used for all months in year $K$. Resampling of blocks of data is known as the moving-blocks bootstrap first introduced by Kunsch (1989). Noise* $\left(t_{m, K}\right)$ term is added to the original smooth curve from (1) and a new hypothetical low frequency component, $F^{*}\left(t_{m, K}\right)$, is extracted and stored. We analyze a sample of 1000 time series of $F^{*}\left(t_{m, K}\right)$ and calculate several statistical characteristics related to the trend variability including: the mean change of total ozone over separated 10-year blocks, the rate of ozone change in the moving 5 -year blocks, and the ozone departure at the end of time series. These values are sorted in ascending order and point No. 25 and No. 975 define the $95 \%$ confidence range for the estimated values.

\section{Results}

The zonal monthly means are calculated averaging the daily data taken from the COST-726 total ozone data base over Europe. The relative deviations for the zonal monthly means are derived as differences between the actual zonal monthly means and the overall monthly means for the period 19501978 (pre-satellite era of the ozone observations) expressed as percent of the overall means. The trend curves are calculated by the kernel smoothing with bandwidth 8 -year as it was discussed in previous section. In this section we focus on behavior of the smooth curves rather than on individual monthly data. Further in the text we discuss temporal and 

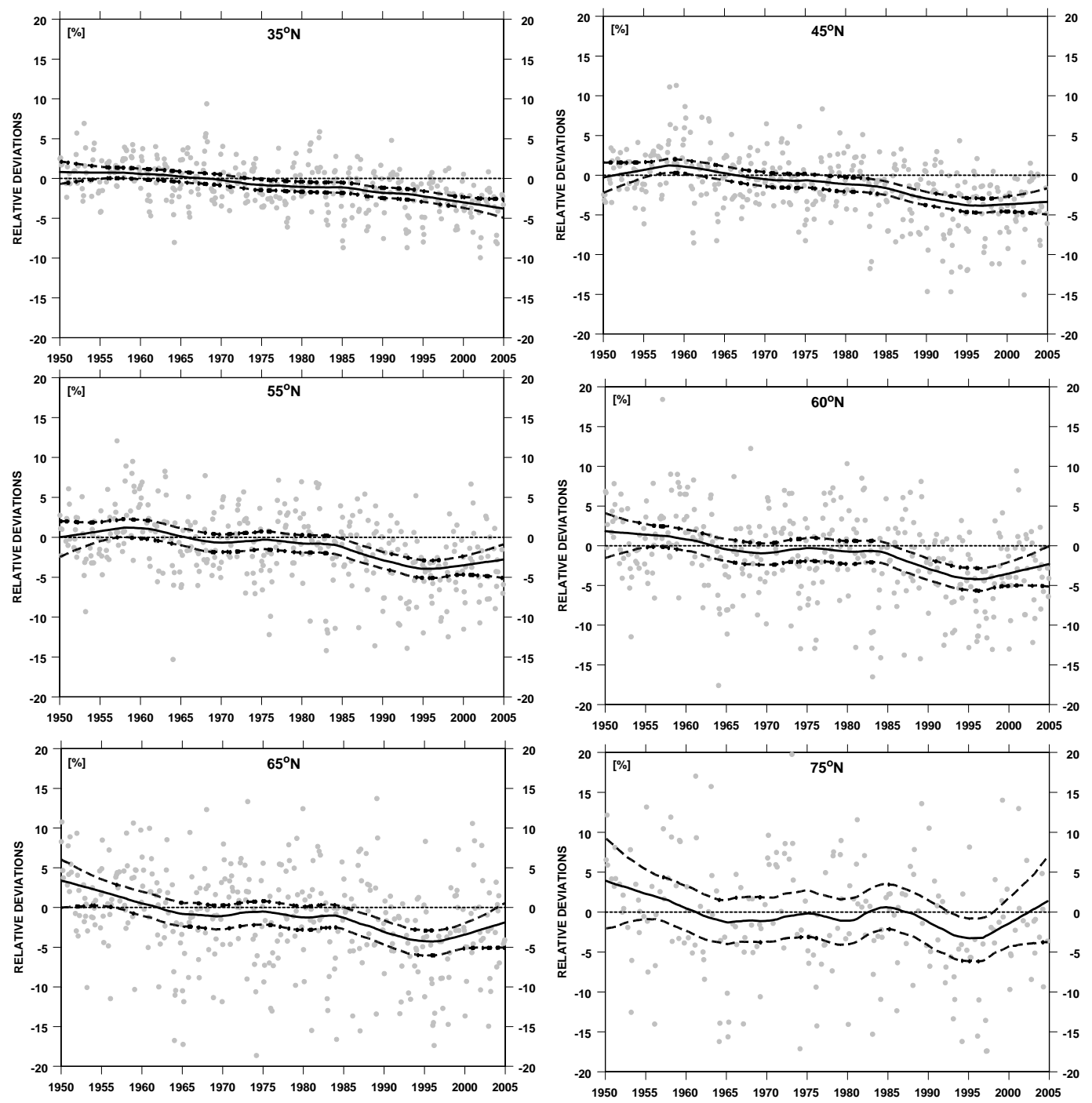

Fig. 4. Relative deviations of zonal monthly means in cold seasons (October-next year April) and the trend curve (solid curve) derived by the kernel smoother for various latitudinal belts in Europe. The dashed curves show $95 \%$ confidence interval for the smoothed values.

zonal changes in the trend patterns over Europe. Figures 4 and 5 show the trend curves extracted from the relative deviations of zonal monthly means for the cold and warm subseasons, respectively.

It is seen that the statistically significant negative departures of zonal mean total ozone appeared in the mid 1980s. Until the end of the analyzed period ozone stays below its pre-satellite era values. It seems that the ozone lowering stops around 1995. No further thinning of the ozone layer during the last decade (1995-2004) over Europe could be inferred from the trend curve patterns. Some insights of a trend turnaround in the mid 1990s should be noted especially in higher latitudes ( $>55^{\circ} \mathrm{N}$ for the cold periods, $\geq 65^{\circ} \mathrm{N}$ for the warm period). A declining tendency could be hypothesized for the zonal bands with latitudes $\geq 60^{\circ} \mathrm{N}$ during cold sea- sons in first two decades of the ozone record. The width of 95\% confidence range of the trend curve is enlarged at the end and beginning of the time series and for higher latitudes regions. Thus, these findings cannot be supported by a rigorous statistical test.

The trend curve is divided into moving 5-year blocks to find a trend variability. Thus, moving trend values will be calculated for time intervals: 1950-1955, 1951-1956, ..., 1998-2003, 1999-2004. The trend value (in \%/10-yr.) in month $t_{m, K}$ is obtained as the difference between the trend curve values in this month and that 5 -year earlier divided by the length of the time interval;

$\operatorname{Trend}\left(t_{m, K}\right)=2\left(F\left(t_{m, K}\right)-F\left(t_{m, K}-5 y r\right)\right)$

Figure 6 (cold seasons) and Fig. 7 (warm seasons) illustrate the trend variability for the same latitudinal bands as 

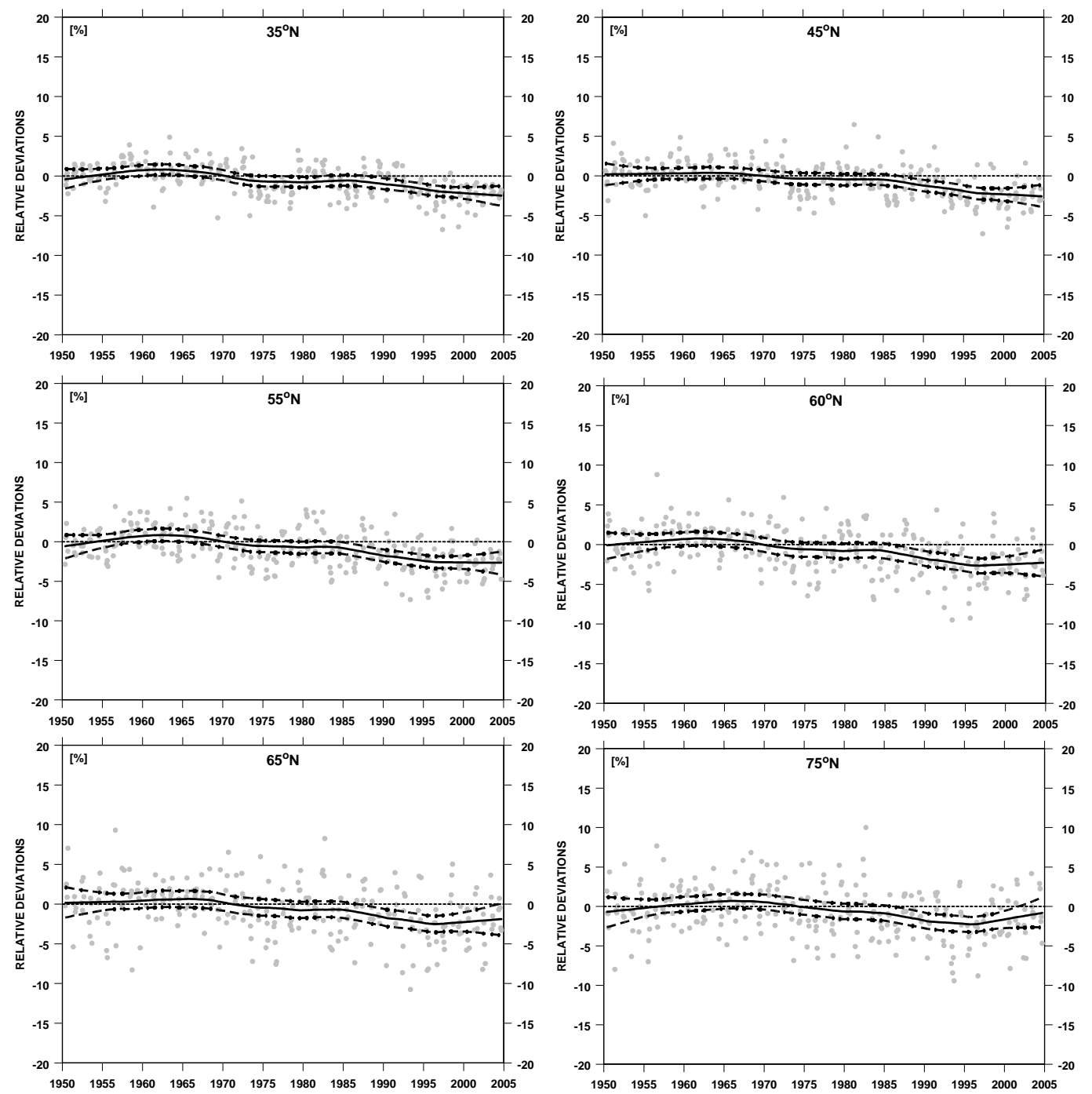

Fig. 5. Same as Fig.4 but zonal means in warm seasons (May-September).

those used in Fig. 4 and Fig. 5. Pattern of the trend variability is similar almost in all zonal bands, i.e., maxima at the beginning, middle, and at the end of the data period, and minima in the 1960s-early 1970s, and in the 1980-early 1990s. Only the trend pattern for cold seasons in the $35^{\circ} \mathrm{N}$ band suggests steadily decline of total ozone throughout the whole time series. It seems that changes in the atmospheric chemistry are not responsible for the continuation of the decline tendency in this region. The effective chlorine loading in the stratosphere is now decreasing, i.e., it acts in opposite direction causing at least no further decline of ozone, e.g., Chipperfield at al. (2007). Thus, changes in the atmospheric dynamics are possible source of the ozone behavior in the southern Europe during the cold subperiods. More frequent transport of the ozone poor tropical air masses is possible source of the ozone trend there.
The $95 \%$ confidence range of the trend estimates increases from $\pm 1 \%( \pm 1.5 \%)$ per decade to $\pm 2 \%( \pm 4 \%)$ per decade from the lowermost to the uppermost zonal band during warm (cold) seasons. The mean trend values over the zonal bands (marked as thick line in Fig. 6 and Fig. 7) are not large, i.e., $\sim-1.5 \%(\sim-3 \%)$ per decade at the trend minima and $\sim 1.0 \%(\sim 3 \%)$ at the trend maxima during warm (cold) seasons. Thus, statistically significant negative trends are found for small parts of the analyzed 55-yr time series, i.e., between late 1980s and mid 1990s and for shorter periods between 1960s and 1970s. Statistically significant positive trends do not appear over the analyzed bands. However, it is worth noting large upward tendency that is manifested at the end of time series over the high latitudinal regions especially during cold seasons. The trend is still negative in recent decade (1995-2004) over the $35^{\circ} \mathrm{N}$ band during cold seasons. 

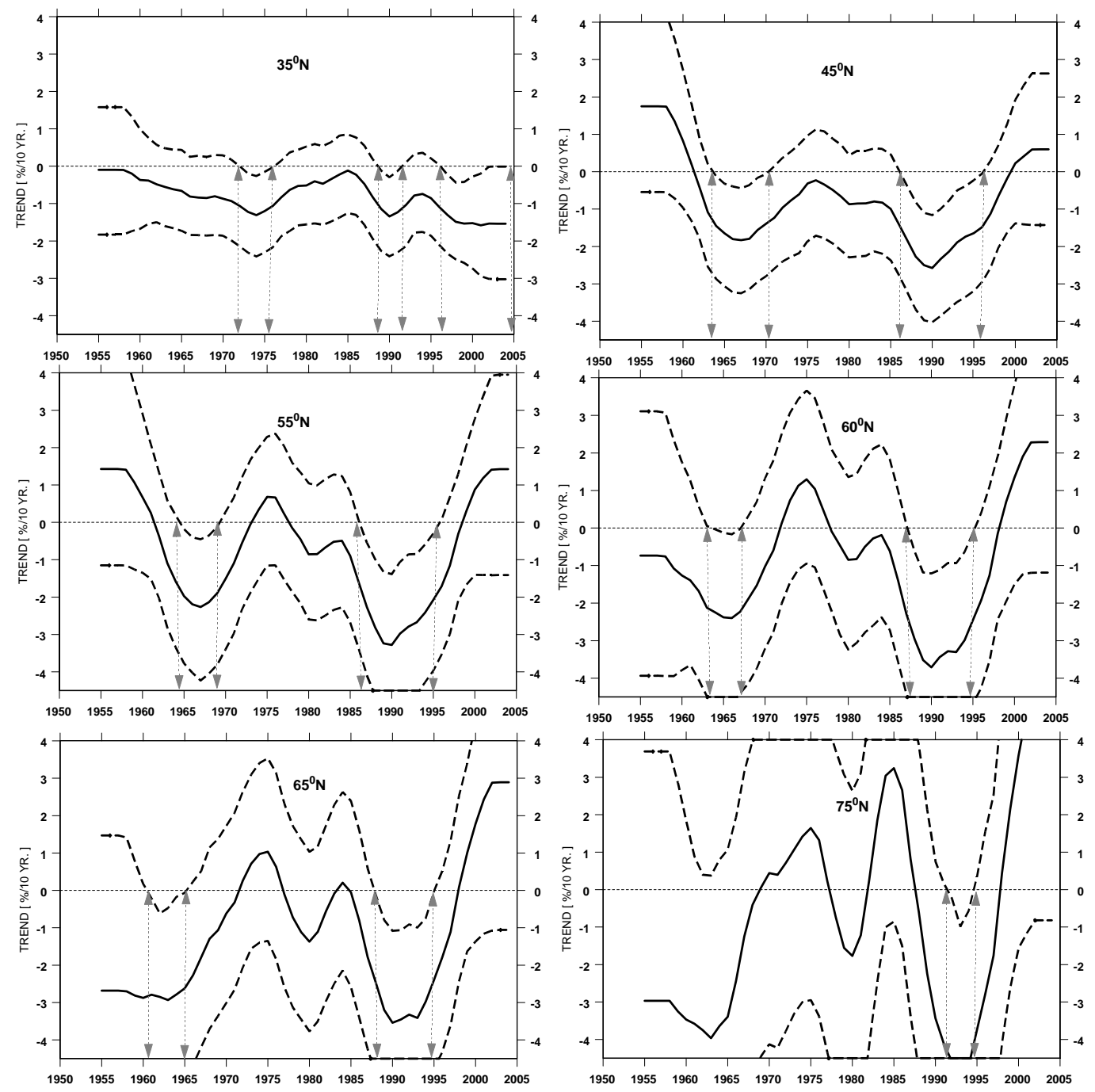

Fig. 6. Trend (\%/decade) in 5-year moving blocks in cold seasons - solid curve. Dashed curves show 95\% confidence range of the trend estimates. Arrows mark period with statistically significant values.

Figure 8 (cold seasons) and Fig. 9 (warm season) illustrate spatial variability of the ozone trend over Europe in the disjoined decade blocks since 1955 and the ozone level at the end of data (2004). The ozone time series for each grid point is analyzed independently, and the trend values for 10-year blocks are calculated using the same methodology which was applied for the zonal total ozone means. Dashed regions mark areas where the estimated values are not statistically significant at $95 \%$ confidence level. The confidence limits are derived by the block bootstrapping.

The statistically significant negative trends are found for wide European areas only in the period 1985-1995. Some regions with negative trends appeared in earlier decades but their areas were rather limited, for example, Great Britain and the eastern part of the Mediterranean Sea in warm seasons 1964-1974, Southern France, Spain, the western part of the Mediterranean Sea, and Northern Africa in cold seasons 1975-1984. The statistically positive trends are found only during warm seasons 1995-2004 over Svalbard archipelago. It is worth noting appearance of statistically significant trend in cold seasons 1994-2005 over the central/southern part of the Mediterranean Sea and Northern Africa.

Total ozone at the end of time series stays below presatellite (1978) mean level over the low and mid-latitude areas with the largest decline in the southern part of Europe ( $\sim 4-5 \%$ decline during cold seasons) and central Europe ( $\sim 3-3.5 \%$ decline during warm seasons). It seems that during last two decades substantial changes in the trend pattern occurred in the high latitudes regions of Europe especially in the cold seasons as the ozone depleted areas disappeared at the end of the time series that was followed by a large ozone depletion in the 1984-1995. However, larger uncertainties 

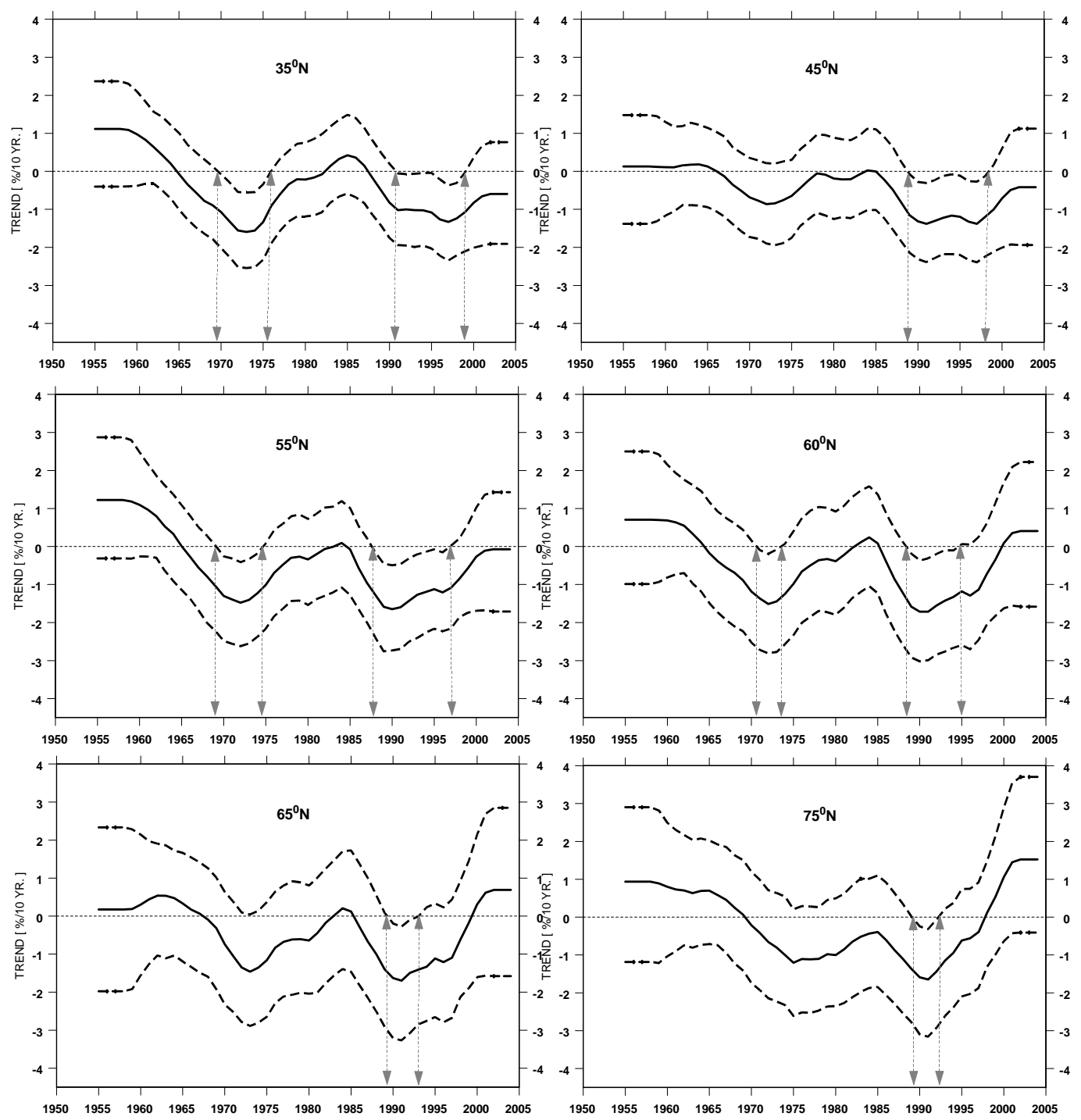

Fig. 7. Same as Fig. 6 but for the zonal means in warm seasons.

of the statistical estimates for the high latitudes region do not allow to draw convinced (statistically significant) conclusion.

\section{Summary and conclusions}

Thinning ozone layer has focused interest of scientific community for almost two decades as expected increases of UVR reaching the Earth surface were linked with detrimental ecological aspects. The ozone trend analyses have been targeted to estimation of an anthropogenic component of the ozone trend. Many efforts have been put to parameterize "natural" variations in ozone (e.g. Fioletov et al., 2002; Steinbrecht et al., 2003; Dhomse et al., 2006; Wohltmann et al., 2007). Thus resulting trend pattern after elimination of the "natural" fluctuations are thought to be an effect of anthropogenic forcing related to an increase of the atmosphere loading by the human made substances destroying ozone layer. However, for an estimation of danger of thinning ozone layer we need also information of the total ozone trend pattern comprising both the anthropogenic and "natural" forcing. Here, we present an analysis of the long-term variability of total ozone over Europe based on the reconstructed data extending back to 1 January 1950. The data base was built within the objective of the COST-726 project activity (Krzyścin, 2008). The basic idea of the proposed trend model is to fit proper smooth curve to the scattered monthly mean data and evaluation of the trend variability from the differences between the curve's values at selected intervals. The confidence intervals for estimates of the trend values are calculated by the block bootstrapping of the model residual term.

Inspection of the spatial/temporal long-term ozone variability over Europe suggests significant changes of the ozone 

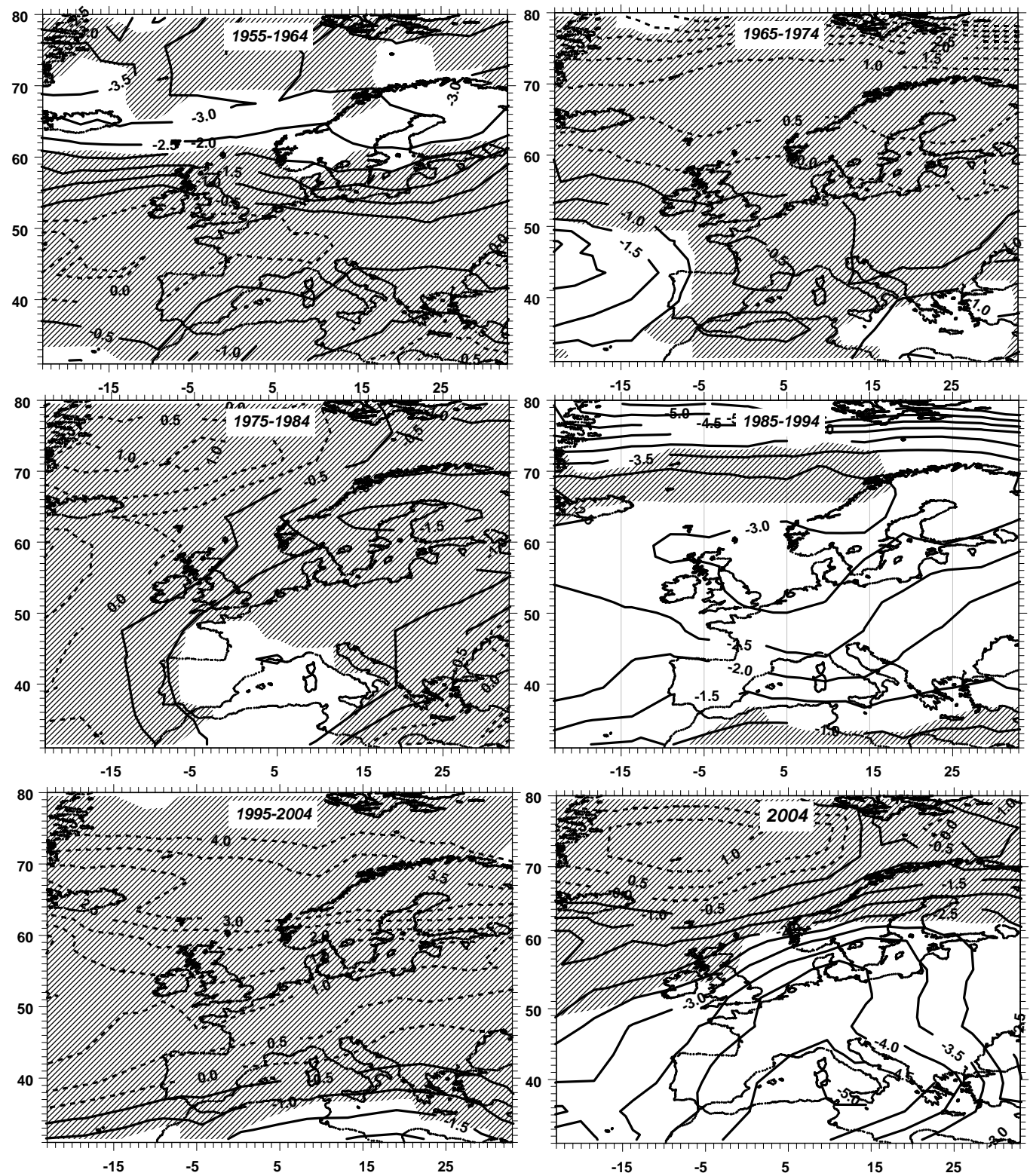

Fig. 8. Trends in 10-year disjoined blocks (\%/10-year), and the relative deviation of total ozone in 2004 (in \% of ozone value in pre-satellite era) for cold season. The dashed area marks region where estimates are not statistically significant at $95 \%$ confidence level.

field over Europe in recent decades. Present ozone decline (in 2004, the end of time series) relative to the ozone level before the satellite era of observations is not dramatic. Maximum decline is found $\sim 5 \%$ and $\sim 3.5 \%$ in the cold (Octobernext year April) and warm (May-September) subperiods of the year, respectively. The statistically significant negative ozone trends over wide areas are mainly found in the mid 1980s up to mid 1995s. For high latitude regions the trend overturning could be inferred in last decade (1995-2004) as the ozone depleted areas are not found there at the end of time series. It suggests a compensation of a large ozone depletion that happened before the mid 1990s over high north latitudes.
Thus an importance of dynamical processes in forming the long-term pattern of the ozone variability should be stressed here. Substantial thinning (up to $-3 \% /$ per decade) of ozone layer could be found for some areas before 1980s, for example region along the Arctic circle in 1955-1964. It was probably related to an impact of the nuclear weapons tests in the atmosphere on the ozone layer that were banned in 1963.

It is worth mentioning from perspective of protection against excessive UVR that present total ozone level over wide areas of central and southern part of continental Europe in the warm season, i.e., in period with naturally high surface UVR, is still 3\% below its undisturbed level before 1979 . 

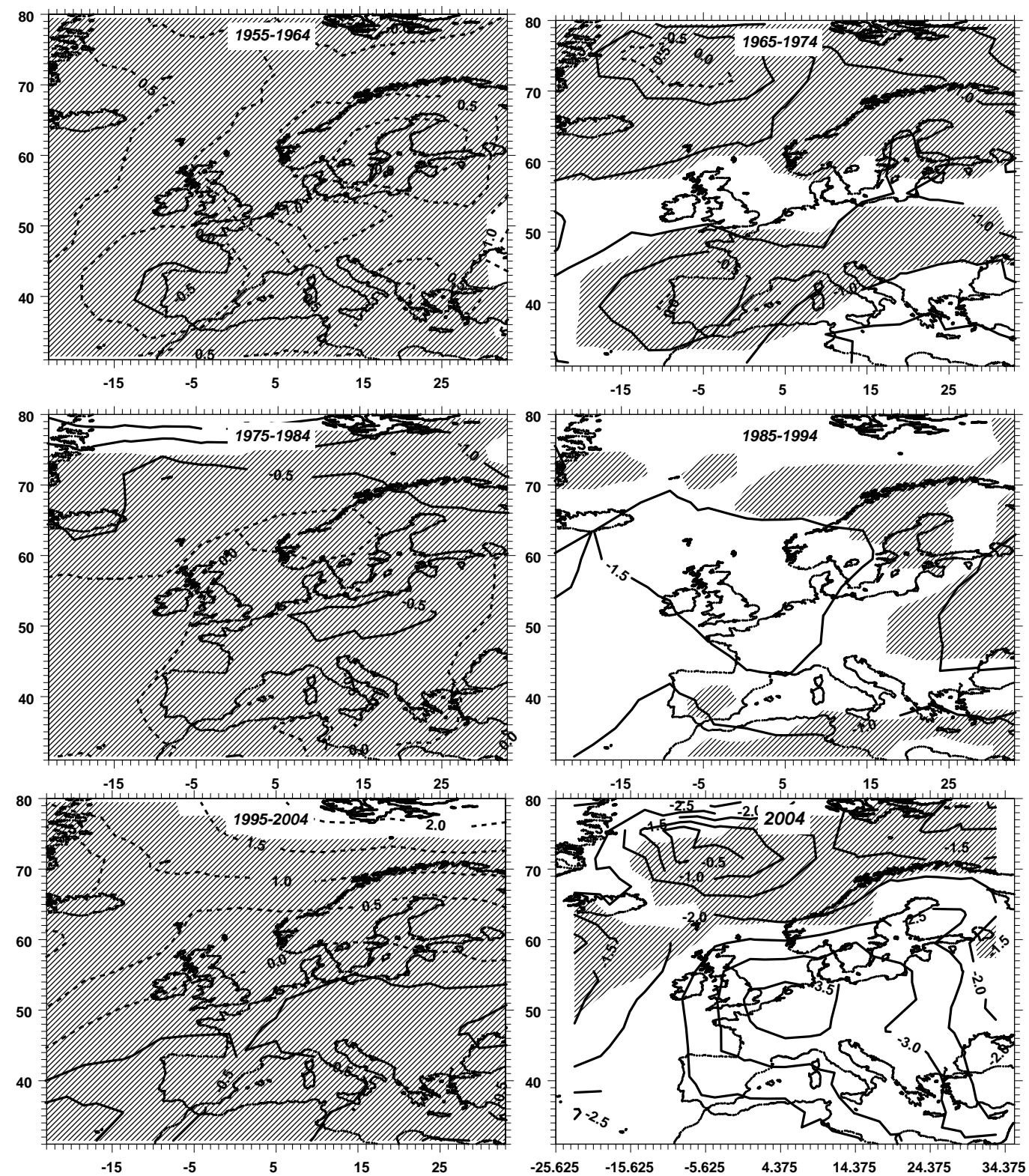

Fig. 9. Same as Fig. 8 but for warm season.

Moreover, present ozone level is still depleted over many winter resorts over southern Europe and northern Africa during cold seasons. What is most alarming negative trends still exist in last decade for some isolated areas there, like the southern part of the Mediterranean Sea. Thus, further public informing of danger related to the UV overexposes is still vital issue.

Acknowledgements. The study has been triggered by the COST-726 action objectives and funded by the Ministry of Sciences and Higher Education under grant No. 2 P04D06728. Authors would like to thank G. Bodeker for providing NIWA data. The authors appreciate the reviewers' comments that help to improve the paper.
Edited by: M. Blumthaler

\section{References}

Bais, A. F., Lubin, D., Arola, A., Bernhard, G., et al.: Surface ultraviolet radiation: past, present, and future, Chapter 7, in: Scientific Assessment of Ozone Depletion: 2006, Global Ozone Research and Monitoring Project, Report No. 50, World Meteorological Organization, Geneva, Switzerland, 2007.

Bodeker, G. E., Scott, J., Kreher, K., and McKenzie, R.: Global ozone trends in potential vorticity coordinates using TOMS and GOME intercompared against the Dobson network: 1978-1998, J. Geophys. Res., 106, 23 029-23 042, 2001. 
Bodeker, G. E., Shiona, H., and Eskes, H.: Indicators of Antarctic ozone depletion, Atmos. Chem. Phys., 5, 2603-2615, 2005, http://www.atmos-chem-phys.net/5/2603/2005/.

Borkowski, J. L.: Homogenization of the Belsk UV-B time series (1976-1997) and trend analysis, J. Geophys. Res, 105, 48734878, 2000.

Borkowski, J. L.: Variations of UV-B radiation, ozone, and cloudiness at different time scale; a wavelet analysis, Acta Geophys. Pol., 50, 109-117, 2002.

Bruce, A. and Gao, H.-Y.: Applied wavelet analysis with S-PLUS, Springer Verlag, New York, 1996.

Chipperfield, M. P., Fioletov, V. E., Bregman, B., Burrows, J., et al.: Global ozone: Past and present, Chapter 3, in: Scientific Assessment of Ozone Depletion: 2006, Global Ozone Research and Monitoring Project, Report No. 50, World Meteorological Organization, Geneva, Switzerland, 572 pp., 2007.

den Outer, P. N., Slaper, H., Matthijsen, J., Reinen, H. A. J. M., and Tax, R.: Variability of ground-level ultraviolet: model and measurement, Radiat. Protect. Dosimetry, 91, 105-110, 2000.

Dhomse, S., Weber, M., Wohltmann, I., Rex, M., and Burrows, J. P.: On the possible causes of recent increases in northern hemispheric total ozone from a statistical analysis of satellite data from 1979 to 2003, Atmos. Chem. Phys., 6, 1165-1180, 2006, http://www.atmos-chem-phys.net/6/1165/2006/.

Fioletov, V. E., McArthur, L. J. B., Kerr, J. B., and Wardle, D. I.: Long-term variations of UV-B irradiance over Canada estimated from Brewer observations and derived from ozone and pyranometer measurements, J. Geophys. Res., 106, 23 009-23 028, 2001.

Fioletov, V. E., Bodeker, G. E., Miller, A. J., McPeters, R. D., and Stolarski, R.: Global and zonal total ozone variations estimated from ground-based and satellite measurements: 1964-2000, J. Geophys. Res., 107, 4647, doi:4610.1029/2001JD001350, 2002.

Friedman, J. H.: Multivariate adaptive regression splines, The Annals of Statistics, 19, 1-50, 1991.

Harris, J. M., Oltmans, S. J., Bodeker, G. E., Stolarski, R., Evans, R. D., and Quincy, D. M.: Long-term variations in total ozone derived from Dobson and satellite data, Atmos. Environ., 37, 31673175, 2003.

Kaurola, J., Taalas P., Koskela T., Borkowski J., and Josefsson, W.: Long-term variations of UV-B doses at three stations in northern Europe, J. Geophys. Res., 105, 20 813-20 820, 2000.

Kopke, P., De Backer, H., Bais, A., Curylo, A., et al.: Modelling solar UV radiation in the past: Comparison of algorithms and input data, Proc. of SPIE, 6362, doi:10.1117/12.687682, 2006.

Krzyścin, J. W., Jarosawski, J., and Rajewska-Wiêch, B.: Beginning of the ozone recovery over Europe? - Analysis of the total ozone data from ground-based observations, 1964-2004, Ann. Geophys., 23, 1695-1695, 2005,

http://www.ann-geophys.net/23/1695/2005/.
Krzyścin, J. W.: Change in ozone depletion rates beginning in the mid 1990s: trend analyses of the TOMS/SBUV merged total ozone data, 1978-2003, Ann. Geophys., 24, 493-502, 2006, http://www.ann-geophys.net/24/493/2006/.

Krzyścin, J. W.: Statistical reconstruction of daily total ozone over Europe 1950 to 2004, J. Geophys. Res., 113, D07112, doi:10.1029.2007/JD008881, 2008.

Kunsch, H. R.: The jacknife and the bootstrap for general stationary observations, Ann. Stat., 17(3), 1217-1241, 1989.

Oltmans, S. J., Lefohn, A. S., Harris, J. M. et al.: Trends of ozone in the troposphere, Atmos. Environ., 40, 3156-3173, 2006.

Reinsel, G. C., Weatherhead, E. C., Tiao, G. C., Miller, A. J., Nagatani, R. M., Wuebbless, D. J., and Flynn, L. E.: On detection of turnaround and recovery in trend for ozone, J. Geophys. Res., 107(D10), 4078, doi:10.1029/2001JD000500, 2002.

S-Plus 4 Guide to Statistics, Data Analysis Products Division MathSoft, Inc., Seattle, Washington, 1997.

Steinbrecht, W., Hassler, B., Claude, H., Winkler, P., and Stolarski, R.: Global distribution of total ozone and lower stratospheric temperature variations, Atmos. Chem. Phys., 3, 14211438, 2003, http://www.atmos-chem-phys.net/3/1421/2003/.

Weatherhead, E. C., Tiao, G. C., Reinsel, G. C., Frederick, J. E., DeLuisi, J. J., Choi, D., and Tam, W.: Analysis of long-term behavior of ultraviolet radiation measured by Robertson-Berger meters at 14 sites in the United States, J. Geophys. Res., 102, 8737-8754, 1997.

Weatherhead, E., Reinsel, G. C., Tiao, C., Meng, X.-L., Choi, D., Cheang, W.-K., Keller, T., DeLuisi, J., Wuebbles, D. J., Kerr, J. B., Miller, A. J., Oltmans, S. J., and Frederick, J. E.: Factors affecting the detection of trends: Statistical considerations and applications to environmental data, J. Geophys. Res., 103 17 149-17 161, 1998.

Wohltmann, I., Lehmann, R., Rex, M., Brunner, D., and Mader, J. A.: A process-oriented regression model for column ozone, J. Geophys. Res., 112, D12304, doi:10.1029/2006JD007573, 2007.

World Meteorological Organization (WMO): Scientific Assessment of Ozone Depletion: 2002, Global Ozone Research and Monitoring Project, Report No. 47, Geneva, Switzerland, 2003.

World Meteorological Organization (WMO): Scientific Assessment of Ozone Depletion: 2006, Global Ozone Research and Monitoring Project, Report No. 50, World Meteorological Organization, Geneva, Switzerland, 2007. 